\title{
Jerusa: a senhora barroca
}

\author{
Amálio Pinheiro' \\ https://orcid.org/0000-0001-8381-7304 \\ I - PUC-SP \\ São Paulo (SP), Brasil
}

Resumo: Jerusa Pires Ferreira incorporava, do pequeno ao grande, do visível ao invisível, num ir-e-vir alegre e contínuo, as relações entre o sertão e o mundo, as grandes narrativas medievais e as mitopoéticas do cordel, as mitologias fáusticas e sua tradução desviante no Brasil e América Latina, via processos múltiplos de voz e grafia contidos na sua "cultura das bordas" e nas "armadilhas da memória". Tudo o que constitui o afã plutônico de assimilação exposto por Lezama Lima como o "Senhor Barroco", e conforme os níveis dos procedimentos de construção barrocos analisados por Haroldo de Campos.

Palavras-chave: cultura das bordas; tradução; mitopoéticas; barroco; mestiçagem.

Abstract: Jerusa: The Baroque Lady - Jerusa Pires Ferreira embodied, from the small to the large, from the visible to the invisible, in a joyful and continuous "toing and froing," the relationships between the hinterland and the world, the great medieval narratives and the mythopoetics of the corde/ literature, the Faustian mythologies and their deviant translations in Brazil and Latin America, through multiple voice and script processes contained in her "culture of borders" and in the "memory traps." All that constitutes the Plutonic desire for assimilation described by Lezama Lima as the "Baroque Man," and according to the levels of baroque construction procedures analyzed by Haroldo de Campos.

Keywords: culture of borders; translation; mythopoetic; baroque; miscegenation.

\section{Ritmo e biografia}

A conduta e as atitudes vocais e escriturais de Jerusa Pires Ferreira expandem a noção de texto e a vinculação entre texto e sua biografia. Jerusa esbanjava, no canto, na fala e na voz, em corpo e pensamento, a alegria de ser brasileira sendo internacional. Desdobrava uma potência natural e nativa para conviver com figuras extraordinárias no plano mundial, com quem travava amizade cotidiana, a quem traduzia e publicava (tais como Paul Zumthor, Henri Meschonnic, Ivanov, Meletínski, Martín-Barbero, Desiderio Navarro etc.), e, conjuntamente, com pessoas de toda extração social, parentes próximos 
e afins, secretárias, inúmeros alunos, mais um grande painel de cantores, cordelistas e habitantes dos sertões e periferias. E uma penca infindável de amigos.Tudo isso era colocado em circulação afetiva, de um modo qualitativo e composicional, que desafiava, na materialidade do cotidiano, as velocidades e os saberes. Isto quer dizer que os gestos gráficos e orais se entrosavam aos gestos de todo dia. Estes saberes eram encadeados a partir de nexos miúdos, distantes, mas vertiginosos: as teorias sobre ritmo que Meschonnic elaborava sobre a escritura de Espinosa e sobre o traduzir poderiam provir, por exemplo, muito mais da garganta aliterante de um sertanejo (mais próximo por isso de um João Gilberto) do que de um homem letrado.

O conhecimento jerusiano, como queria García Lorca, era um batimento cardíaco que subia pelas plantas dos pés e saía pela voz, ininterruptamente. Alcança a Jerusa o que Julio Cortázar (1968, p. 43) dizia de Lezama Lima: “Um primitivo que sabe de tudo. [...] Entre o saber de Lezama e o de um europeu há a diferença que vai da inocência à culpa." Jerusa é uma dessas grandes primeiras senhoras, desde os primeiros começos do continente ouvindo, reunindo e traduzindo pássaros. Esse estado presente de atenção aos ritmos da tribo impõe um continuum entre texto e biografia, vida nos processos criativos, o internacional no regional. Jerusa situa suas Bordas como uma alegria da "pertença múltipla" e uma "cosmopolítica": "Poderíamos até dizer que estamos preparados para embarcar, em certo momento, no ônibus, à espera da Falsa Loira de Carlos Reichenbach ou mesmo participar do mundo circense de Mazzaropi" (FERREIRA, 2010, p.18). Segundo Jakobson: "Cada pormenor da vida transforma-se, no instante, em fato simbólico. [...] Apaga-se, desse modo, o limite entre o mito poético e a obra comum" (JAKOBSON \& POMORSKA, 1985, p.146); complica-se a separação entre ficção e realidade, signo poético e vida diária. Maiakóvski explicava como começava a compor seus poemas, de modo a interligar os gestos do caminhar e fato poético:

E eis-me caminhando, balançando os braços e mugindo, ainda quase sem palavras, ora encurtando o passo, para não estorvar os mugidos, ora mugindo mais depressa, no ritmo dos passos. Assim se desbasta e se forma o ritmo, base de todo o trabalho poético e que passa por ele numa zoada. (JAKOBSON \& POMORSKA, 1985, p. 76-7).

Jerusa trabalhava essas células rítmicas, que estruturam, em meio à fixidez semântica dos conteúdos, os andares, as vozes e o impresso. Abre-se um panorama das culturas de antes das separações por gêneros e disciplinas e onde tais fronteiras ainda são bastante porosas.

Havia em Jerusa, nessa preferência pelas vocalidades nômades frente aos conteúdos, um movimento do feminino que encaixava as séries do mundo nas séries telúricas do sertão: não seria possível reler as narrativas medievais e fáusticas nas Américas Latinas sem essa correlação de forças rítmicas entre formas de pensamento mais mentais (os dilemas duais do Ocidente) e aquelas saídas da voz no ambiente acústico 
da paisagem cultural. Seus trajetos (para lembrar de coisas bem recentes), que ligavam Ivanov em Chicago e Elomar em São Paulo, os contos russos e as oralidades nordestinas, não tinham nenhuma solução de continuidade e se realizavam como uma necessidade vulcânica (vulcânica no sentido criterioso de que brotavam de uma irrupção de formas significantes em outros ambientes) que vinculava as narrativas universais às memórias locais. Por isso podia entrar numa sala de aula cantarolando e contando causos: sem esse tutano dos ritmos armazenados nas reentrâncias das culturas barroco-mestiças não é possível transmitir saberes, pois estes são a tradução dos códigos universais de todas as linguagens para os códigos específicos do continente, dados já como experimentos locais vivos. Ou seja: interação intensa entre diacronia e sincronia, que integra as camadas tectônicas à superfície plana do atual.

Deriva daí uma tradução cultural ao mesmo tempo proliferante e eruptiva. Isto fará muita falta à Academia, especializada esta tendencialmente em separar o conhecimento abstrato interno e disciplinar, de um lado, nas salas de aula, das formas existentes em ação afetiva externa, nas ruas e bairros, onde habitam em relação rítmico-acústica na paisagem pessoas, bichos, plantas e objetos. Isso significa optar por uma "História viva", em que se dignifica o que é pensado dentro da vida das coisas em ação no mundo. Daí a necessidade de superar as oposições: "ultrapassar dicotomias empedradas como a famosa popular versus erudito, passando a entender tudo isto como um processo contínuo de transmissão e de uma espécie de tradução cultural permanente" (FERREIRA, 2014, p. 17). Nesse contexto pluralmente relacional de incorporações tradutórias múltiplas, Jerusa problematiza, inclusive, o conceito de "matriz", evitando assim as fáceis generalizações essencializantes:

A noção de "matriz", sempre considerada em termos relativos, tenta explicar o funcionamento oral/escrito/impresso/oral, deixando de lado a concepção de uma espécie de memória despótica, de uma originalidade da criação popular em si mesma, e que é até considerada espontânea por alguns pesquisadores do folclore. (FERREIRA, 2014, p. 17)

A ideia de um continuum em arquipélago (de camadas em palimpsesto geologicamente semoventes) exclui, nos próprios termos, de um golpe, via nexos rítmicos, as oposições entre o originário e o contemporâneo. A exagerada e apressada menção ao dito contemporâneo, como mera muleta lexical, esvazia-o ou absolutiza-o como uma espécie de origem às avessas. Não por acaso Jerusa começava a traduzir, de Meschonnic, Spinoza - Poème da la pensée (2017) onde se contestam com veemência as análises conteudistas sobre o pensamento espinosista, sem se perceber a suma importância das figuras do ritmo em sua filosofia: “...o léxico não é a linguagem. A linguagem é infinitamente mais que um léxico". Meschonnic (2017, p. 148) acentua, na maioria desses autores, 
...um desconhecimento da diferença radical entre um pensamento do contínuo, em Espinosa (o contínuo afeto-conceito; o contínuo entre teoria do conhecimento, ética e política) e um pensamento da heterogeneidade das categorias, aquela das Luzes, que separa, cria as ciências regionais, das quais nossas disciplinas universitárias são o prolongamento. [...]

\section{Os Faustos crioulos de Jerusa}

Jerusa pratica assim o que Lezama Lima (1988, p. 18-41) chamou de o grande "Eros relacionável" da América Latina, o "contraponto de imagens" que desindividualiza os sujeitos na direção proeminente da natureza e da cultura, onde as diferenciações advindas das incorporações tradutórias vêm acompanhadas de camadas sacro-profanas e melodramáticas de humor e malícia, de afetos dançantes, tal como, por exemplo, nos Faustos crioulos, gauchos e nordestinos. Mas trata-se sempre de recriações desviantes, que modificam, em outra situação de espaço, tempo e história, a chamada relação pactária entre Fausto e Mefisto, no trânsito entre o literário, o popular e o massivo:

O que mais fascina no Fausto gauchesco de Estanislao del Campo [...] é este humor gracioso, a recuperação adequada que insere a lenda Fáustica no mundo gaúcho, é a sutileza de certas tomadas melodramáticas. [...] Ao apresentar-se este Fausto, fala-se até de humor gaúcho e de malícia chispeante. Poderíamos, numa comparação ousada, aproximar sua composição de certos procedimentos do cinema popular brasileiro de Mazzaropi. Há neste Fausto de del Campo, mais de uma vez, a referência textual ao romanceiro ibérico. [...] Todos os signos do mundo campeiro são trazidos para selar a contemplação deste outro universo: o mar, um desafio. (FERREIRA, 2010a, p. 318)

Tudo isso, mostra Jerusa, "realizado em regime de payada (gênero popular da cantoria)". (FERREIRA, 2010a, p. 318). Há aqui, neste Fausto em folhetim de 1866, uma miscelânea de vários gêneros enxertados. Neste jogo entre perdição e salvação, treva e luz, noite e dia, Jerusa parece apontar, via tradução recriativa, para uma outra "capacidade de gerir a coincidência dos opostos" (FERREIRA, 2010a, p. 319), em que o gesto do "diferir luciferino" de Haroldo de Campos (2013), de militância seletiva radical, é levado, com Jerusa, alegremente, por uma espécie de motim da garganta multitudinária popular, na direção desses agentes tradutórios (meio-gentes, meio-plantas, meio-onças mais do que simplesmente sujeitos) situados nas entranhas e moléculas sacro-pagãs das oralidades e da vozearia nativas. Basta ler a primeira décima do Fausto (1870) de Estanislao del Campo para constatar o gozo da linguagem malhada de gauchismos, arcaísmos e gírias de arrabalde. O escritor argentino parece ter radicalizado processos carnavalizantes já presentes no Fausto de Goethe. 
Não pode ser mera coincidência que quase todos os Faustos ibero-americanos, em diversas medidas e formatos, sejam assimilações erótico-farsescas - veja-se, entre tantos Faustos de todos os tipos, de Machado de Assis a Guimarães Rosa, o caso do Faustino (1987), de Donaldo Schüler, em que o diminutivo brilha risível e paródico num simples fonema. Trata-se de um outro modo de apostar com a morte e com Mefisto. (Como nesses blocos caboclo-afro-tupis dos Poemas Negros em Jorge de Lima: "Quando ele vem, vem zunindo como o vento / como mangangá, como capeta, / como bango-balango, como marimbondo. / De onde é que ele vem? / Vem de Oxalá, vem de Oxalá".) A marchetaria colorida de vozes e sílabas encharca, por assim dizer, as narrativas fáusticas com marcas cômicas, carnais e carnavalescas que desmontam, pelo humor polivalente, as contradições e aporias da implacável evolução linear-conteudista do chamado Ocidente moderno. Jerusa, em pessoa e escritura, contradiz essa pretensa direção inexorável de um tempo que caminha, via organização e colonização do progresso, para o futuro, às custas do estar-aqui-e-agora. Há uma política e ética da alegria feminina barroca em que os tempos nunca são apenas modernos, pós-modernos ou contemporâneos, porque não pertencem à história antropocêntrica retilínea, visto que reescrevem com o tráfego das vozes um presente contínuo dentro de toda a natureza. Os ritmos significantes são sempre agentes de passagem e transferência: já não há aqui separação de saberes por disciplinas. Ritmo das falas dos muitos povos, ritmo das folhas, ritmos das marés, ritmo das letras impressas. Jerusa chamou a esse movimento de vocigrafia, a partir das unidades que são os vocemas (FERREIRA, 2006, p. 193-6). Estes congregam o vozerio mesclado presente, e ao mesmo tempo represam as vozes reprimidas e/ou ancestrais. Ouçamos Jerusa:

Encontra-se escondida, na selva inacessível, a voz de povos indígenas, de tantos idiomas que se oferecem, em desafio, aos antropólogos, linguistas, semioticistas. A dimensão insuspeitável desse cosmo nos oferece uma antevisão da complexidade do queé pensar tradição, voz, oralidade, em nosso continente. (FERREIRA, 2006, p. 193-6)

O tremor das vozes se traduz em tremor dos rios e das sílabas e vice-versa num ir-e-vir incessante. Essa é uma poética da cultura em que prevalece a noção de uma composição crescente não progressiva. Não se pode determinar, pelo caráter vertiginoso de suas combinatórias radicalmente barroquizantes, um começo original ou um coroamento futuro. Há aí uma costura das bordas marginais e endêmicas com as narrativas universais, que passam a ser relidas e reativadas, como diferença conexa não idêntica, em outra circunstância, contexto e patamar comunicacional e criativo. Daí que Jerusa insista, ao falar da produção poética em cordel, em seu novo livro vivíssimo depois de sua morte: "tem sido construída sobre um lastro de símbolos e figuras todo um repertório de situações, na persistência dos antigos romanceiros ibéricos, recriados e inovados, a partir das condições do sertão brasileiro" (FERREIRA, 2019, p. 17). Não cabem aí as próteses postiças que não passem pelo crivo da tradição nômade das transmissões orais inscritas nos ambientes. 


\title{
Os códigos e as séries: Haroldo, Lezama, Jerusa
}

Por isso, nesse terreno de trocas entre linguagens, cultura e natureza, Haroldo de Campos demonstra a complexa interação de alguns níveis da ação permanente das manifestações barrocas:

\begin{abstract}
A permanência do barroco ibero-americano é um dispositivo operatório capaz de diferenciação modal dentro do manuseio do código estilístico universal. Esta diferenciação se manifesta em vários níveis; por exemplo, no nível da mescla linguística, no nível dos dados da natureza exuberante e ornamental dos trópicos e no nível do contexto específico da vida colonial. Esta permanência assume o aspecto de uma verdadeira constante formadora da sensibilidade artística latinoamericana (grifos do autor) (CAMPOS, 2001, p. 86).
\end{abstract}

Repare-se que Haroldo insiste na ideia crucial de permanência e constância formadora e fundante desse barroco diferencial e tradutório, que contraria duas tendências centroocidentalizantes: a de se considerar o mesmo apenas como prolongamento do clássico ou do gótico tardio ou ainda como uma ressurgência pós-modernóide evolutiva, sucessiva, linear, epocal e, portanto, unidimensional. Uma característica de base desse barroco ibero-americano está na sua necessária pluridimensionalidade relacional que engolfa e retalha, desde os seus começos ibero-afro-indígenas, pelas reversões e incrustações lúdico-compositivas, os binarismos e os paradoxos.

E aqui entra uma contribuição complementar mas fundamental de Jerusa, distribuída de vários modos por toda a sua obra: "O poeta popular lida com a inserção do tempo mítico em sua circunstância social mais diretamente"(FERREIRA, 2014, p. 87). Esse "mais diretamente" é muita coisa: são todas as afecções entre corpo, voz, ambiente acústico e paisagem cultural. Daí essa interação endêmica, nas Américas, entre crônica diária "ao ar livre" e as narrativas míticas. Por isso Lezama Lima chamou ao barroco de arte da "contraconquista", já nos começos da Colônia, visto que os níveis dos códigos de linguagem, do contexto das séries da cultura e da natureza participante interagem desde os micro-elementos regionais às mitopoéticas universais (ou melhor, os micro-elementos regionais absorvem e "transcriam" antropofagicamente as narrativas lendárias universais). Um aumento de luminosidade numa vogal pode insinuar, por acréscimo de tensão na alegria composicional, uma deriva importante no conjunto da narrativa herdada. A marchetaria colorida de vozes é aqui o "dispositivo operatório" que traduz os Faustos, os contos russos etc. para fora da história oficial, enfatizando a comicidade e sensualidade musical da tradição nordestina ou campeira, e revertendo, por assim dizer, a ordem melancólica da tragédia dual dos sujeitos da ordem e progresso modernos. Daí que, pela presença vocal-afetiva desses "corpúsculos coloridos, em todo americano há um gongorino manso, que explode seu verbo quando passa o vinho, confortável, não trágico como 
o espanhol" (LEZAMA LIMA, 1988a, p. 262-3). Uma intensidade de acento ou reforço de tonalidade em uma sílaba trazem à tona correntes subterrâneas de significação, mudam o compasso rítmico e introduzem um elemento de rigorosa alegria produtiva que acelera e fortalece o conjunto da composição.

Quem conviveu continuadamente com Jerusa sabe que ela incluía, através dessas operações transbarrocas, no próprio cotidiano viageiro e doméstico, os elementos dos quais as oralidades mitopoéticas regionais lançavam mão para digerir as narrativas universais. Isso se dá através de uma combinação vital das séries do cotidiano, da poesia, da cultura e da natureza, englobando os três níveis de ação dos procedimentos barrocos alinhados um pouco acima por Haroldo. Consiste numa poética da cultura trazida para os microcosmos existenciais, em que os "tecidos fáusticos" de Jerusa tornam-se prática molecular nas nervuras do dia a dia. Assim, tratar de uma versão mitológica em cordel, vestir-se com uma estamparia, dar aula, cantarolar etc., qualquer ato e fato ordinário desdobra a tessitura, participa, em ourivesaria, da configuração de uma imagem em arabesco: "os nossos primeiros antecedentes eram prateiros e doceiros" (LEZAMA LIMA, 1988a, p. 104). Os poetas e os prateiros igualmente esculpem essa imagem em contraponto. Desde esses começos, não havia prolongamento nem oposição ao mundo clássico: o barroco já estava instalado nos códigos das linguagens não oficiais e na potência da imagem como arco-íris de relações. Desse modo, Jerusa atualiza Lezama, cuja atenção aos "dados da natureza" expunha a fundação barroca, via alegria solar, das Américas: "O barroco, na nossa América, é o festejo da algazarra excessiva da fruta" (LEZAMA LIMA, 1981, p. 134). Ou em "Oppiano Licario", onde se observa sempre esse transporte de pólens entre séries da cultura e da natureza:

Nossa comida forma parte de nossa imagem [...]. Não é apenas na incorporação das viandas onde o cubano ronda o matagal e suas raízes de muito perto, mas também a mais elaborada das nossas brisas encrespa, como túnicas de igual delicadeza, o ondulante ápice da seda de ananás. (LEZAMA LIMA, 1977, p. 227).

Esse "ondulante ápice da seda de ananás" indica um mundo a ser refeito a partir de uma recombinação tradutória de forças em que os sujeitos participem em escala mirim e secundária. Nas "listas díspares" das proliferações barroquizantes lezamianas os elementos sonoros e visuais das linguagens da natureza têm presença constante. Nada mais jerusiano do que este verso compacto de Lezama Lima (1985, p. 183): "Sentado dentro de mi boca asisto al paisaje". Tudo que é traduzido passa por esse crivo. Os biomas não são um "em si" do lado de fora, mas sim partículas, qual plâncton ou húmus, que enxertam todas as falas. Nessa cultura da natureza ou natureza da cultura, não há isolamento entre voz e vegetação.

Daí que a "cultura das bordas" de Jerusa exija pelo menos três instâncias processuais combinadas: a) a relação tradutória entre narrativas/mitos e a produção mestiça popular tem que experimentar procedimentos que desfaçam as oposições binárias, superando 
ao mesmo tempo os fáceis hibridismos e folclorismos, por meio de transcriações dos códigos universais de linguagem para os códigos interespecíficos endêmicos; b) tal relação implica um conhecimento complexo da força rítmica de todas as linguagens e especialmente da voz, das oralidades e da letra impressa dentro da natureza/cultura; c) tal relação arranca de imagens e memórias magmáticas da cultura.

\section{A alegria como prática política}

Em Jerusa, não se trata nunca de uma alegria qualquer. Trata-se desta como afirmação da potência de existir, compondo relações complexas entre o próximo e o distante, entre o conhecido e o desconhecido, desde as partículas menores e mais invisíveis até os grandes conjuntos de significação temática e política. São os corpúsculos que efetuam as passagens e tramas da composição. É claro que fazemos aqui uma adaptação tropical com Espinosa, para quem a tristeza é sempre política e eticamente de qualidade inferior à alegria e deve ser sempre superada por esta. Vejamos o exemplo marcante do sol, em ação dentro do nível das metamorfoses na natureza. O destaque afetivo não está propriamente apenas no sol a bater na cara e no corpo de alguém, mas na reverberação invasiva das luminosidades nos interstícios relacionais de tudo o que existe e de todas as linguagens, modificando os ritmos e entonações das oralidades que refratam o jogo solar de luz e sombra. Todos os nossos códigos foram alterados também pela presença solar. Não é, como mostra Deleuze (2008, p. 210), uma luz de laboratório, não é a luz dos holandeses, a luz de Bizâncio, a luz dos impressionistas, mas uma luz nossa ao ar livre, com "uma infinidade de intensidades luminosas" próprias. Luz que altera e afeta os signos e a passagem construtiva de um signo a outro. A respeito, diz Haroldo:

Daí a mestiçagem, o fusionismo - muitas vezes mesmo hiper-barroquizante, como o quer Lezama Lima - entre os elementos europeus e os elementos indígenas e africanos no contexto ibero-americano, onde se desempenha nosso manuseio diferencial do código de possíveis desta estilística universal. A 'corrente alternativa' do barroco brasileiro, por exemplo, consiste ao mesmo tempo em dizer um código de alteridades e a dizê-lo num código alterado (grifos do autor). (CAMPOS, 2001, p. 95)

Jerusa é uma especialista nas alteridades conexas dos "códigos alterados", trazidos pelas múltiplas variantes orais e pelas intensidades vocais no continente. A luz e a mestiçagem, porém mestiçagem com feixes de luz reverberantes na paisagem e na voz, alteraram os nossos códigos. Aí se situam as traduções fáusticas jerusianas, entre a voz e a letra, entre o dito/declamado/cantado e o impresso, em contínuo vaivém que abarca as séries cotidianas da "história viva" do sertão e das Américas. Ajuda-nos aqui também Bakhtin (1984, p.354): “O riso e a festa. A cultura dos dias ordinários. [...] Tudo o que 
é autenticamente grande deve comportar um elemento de riso, ou arrisca a tornar-se ameaçador, aterrorizante ou grandiloquente e, em qualquer caso, limitado." Deleuze (2008, p. 313) já toma o assunto pela raiz: "Não há poder alegre".

As vozes do cordel são um gênero misto, desde a cultura do al-andalus, que pertence às miscelâneas versificadas de crônicas folhetinescas de todos os dias. Essa brutal inclusão das partículas vocais micro-estéticas, nas comissuras entre corpo, boca e garganta, na fala diária e no verso em cordel, refez os temas narrativos e duais do Ocidente (tão presentes na ansiedade opositiva de um Doutor Fausto (1947) de Thomas Mann, ou, muito anteriormente, nas dicotomias entre pecado e redenção da Gretchen no Fausto (1827) de Goethe), reciclando-os segundo os modos e formas de conhecimento das culturas mestiças em cujas práticas predominam o humor carnavalizante, os cromatismos musicais, os sabores e os contatos. Quer dizer: a tradução da tradição implica um desvio dos sistemas binários, visto que nestas Américas as almas estavam já endiabradas, tendo em vista a multiplicidade aglutinante da variação diferencial inclusiva. Desse modo, pela tradução criativa desviante, "a imaginação europeia, tanto a greco-latina como a medieval, passam na sua totalidade a uma nova circunstância" (Lezama Lima, 1988a, p. 102). Assim, Haroldo de Campos (1995, p. 4) pode referir-se à "miscigenação transcultural" de Severo Sarduy e Lezama Lima, através do poeta colonial Silvestre de Balboa (espécie de Gregório de Mattos cubano), "pondo em relevo uma significativa apreciação de Cinto Vitier" a respeito do poema "Espejo de Paciencia" (1608):

O que se costuma considerar um extravagante desacerto no poema de Balboa a mescla de elementos greco-latinos com a flora, fauna, instrumentos e mesmo roupas indígenas (lembrem-se as hamadríades "de anáguas") - é o que, a nosso juízo, indica o seu lugar mais significativo e dinâmico, aquilo que o vincula realmente com a história da nossa poesia... (CAMPOS, 1995, p. 4).

Nessa trilha, Jerusa mostra, nos Contos Russos no Sertão, como o cantador e poeta pernambucano Severino Milanês da Silva, ao traduzir em versos o grande Púschkin, em O Romance do Príncipe Guidon e o Cisne Branco, pode "inserir elementos das culturas indígenas brasileiras: "Elas prepararam um líquido com o favo de jati"" (veja-se a saborosa rima em "i" no hemistíquio); e ambientar a forma "Czar" para "César", "recuperando a verdadeira etimologia do poder"(FERREIRA, 2014, p 91). E assim termina o trecho Jerusa, depois de acentuar a relação entre ritmo e sentidos através dessas malhas de traduções na história:

Como a relação apontada do texto de Púschkin com o Vôo da Abelha, que tem a ver com a composição do famoso compositor russo Rímski-Kórsakov, mas poderemos também evocar o voo do mangangá de nosso Sivuca, o notável intérprete do Sertão, na sanfona extraordinária que tanto soava em Paris e no mundo (FERREIRA, 2014, p. 94). 


\title{
A Senhora Barroca
}

Jerusa está numa juntura entre Lezama e Haroldo: expande a exigente militância seletiva tradutória deste último à história das falas e objetos mestiços de um Sertão universal. Lezama desfila um rendilhado de atitudes, situações e objetos da cultura vinculados à paisagem (toda essa relação entre árvores, frutas e sílabas), esse mesmo trançado das bordas barroco-mestiças que Jerusa alinhavava e cujas placas tectônicas movimenta e engasta cotidianamente:

\begin{abstract}
Nossa apreciação do barroco americano estará destinada a precisar: primeiro, há uma tensão no barroco; segundo, um plutonismo, fogo originário que rompe os fragmentos e os unifica; terceiro, não é um estilo degenerescente, porém plenário, que na Espanha e na América espanhola representa aquisições de linguagem, talvez únicas no mundo, móveis para a vivenda, formas de vida e de curiosidade, misticismo que abarca novos módulos para a prece, maneiras de saborear e tratar os manjares, que exalam um viver completo, refinado e misterioso [...] (LEZAMA LIMA, 1988a, p. 229).
\end{abstract}

Em vista desse material telúrico em ebulição e metamorfose, em constante interação, nosso barroco não prolonga o gótico nem se opõe ao clássico [aqui um repúdio a evolucionismos como aqueles de Worringer a Hegel, conforme expôs devidamente Irlemar Chiampi (1988)]. Jerusa parece mesmo que sempre esteve aí, nesse "fui-o outrora agora" pessoano, nessa tessitura das bordas de múltiplos espaços e tempos conjugados:

Esse americano senhor barroco, autêntico primeiro instalado no que é nosso [...] trança e multiplica a linguagem ao desfrutá-la; o degustar do seu viver se aglomera e fervilha. Este senhor americano começou por desfrutar e saborear, peça já bem encravada que, se lhe é extraída, guincha e desentoa. Seu viver se converteu numa espécie de grande orelha sutil, que num canto da sua mui espaçosa sala desenreda os imbroglios e amontoa as folhas simples (LEZAMA LIMA, 1988a, p. 230).

Persiste sempre a necessidade de uma incansável atenção rítmico-afetiva - uma "grande orelha sutil" que aglomera em ziguezague os gêneros, as séries e as linguagens e que remove nas mentes o nódulo básico de toda dominação: a ideologia dos conteúdos e das narrativas separadas, sequenciais e descontínuas. Por isso pode Jerusa expandir até aos regimes de sentido telemáticos a produção popular em cordel, de que emergem mesclas inusitadas:

Os que mergulham nas altas tecnologias, velozes, proliferantes, construindo a cada momento novos ambientes, suportes materiais, condições que interferem na própria maneira de ser e de pensar, esquecem-se de origens e do equilíbrio 
possível entre os pratos de uma balança. A comunicação humana tem em vista a complexidade de processos e relações. [...] Por isso em Cultura não me parece viável a simples ideia de evolução, e nem de reflexo direto do fenômeno às suas práticas (FERREIRA, 2016, p. 83).

São partículas rítmicas de múltiplas formas significantes que nos colocam "diante de um grande painel da vida popular, daquilo que é documento/história e ainda complexa teia imemorial que se expressa através de mitopoéticas" (FERREIRA, 2019, p. 15).

Jerusa é a nossa "Senhora Barroca", de Feira de Santana para o mundo, que baixou e baixará sempre em nossos terreiros e subúrbios.

Amálio Pinheiro é professor do Programa de Estudos Pósgraduados em Comunicação e Semiótica da PUC-SP.

pinheiro@pucsp.br

\section{Referências}

BAHKTIN, M. Esthétique de la création verbale (Prefácio: T. Todorov). Paris: Gallimard, 1984.

CAMPOS, H. de. Três (re) inscrições para Severo Sarduy. São Paulo: Memorial da América Latina, 1995.

Le baroque: la non-enfance des littératures ibéro-americaines - une constante et une perdurance. In: Résurgences baroques (orgs: Walter Moser e Nicolas Goyer). Bruxelas: La Lettre Volée, 2001.

de. Transcriação (orgs: Marcelo Tápia e Thelma Médici Nóbrega). São Paulo: Perspectiva, 2013.

CHIAMPI, I. A história tecida pela imagem. In: Lezama Lima. A expressão americana. São Paulo: Brasiliense, 1988.

CORTÁZAR. J. Para llegar a Lezama Lima. In: Revista Siempre!, México, março de 1968.

DELEUZE, G. En medio de Spinoza. Buenos Aires: Cactus, 2008.

FERREIRA, J. P. Vigília das oralidades. Revista USP, São Paulo, março/maio, 2006.

Cultura das bordas. Ateliê: São Paulo, 2010.

. Fausto no horizonte latino-americano. In: Fausto e a América Latina (orgs: Helmut Gale e Marcus Mazzari). São Paulo: Umanitas/Fapesp, 2010a.

Matrizes impressas do oral. Conto russo no sertão. São Paulo: Ateliê, 2014.

Comunicação popular em lowtech, hightech. In: Jornalismo expandido. Práticas, sujeitos e relatos entrelaçados (orgs: Amálio Pinheiro e Cecília Almeida Salles). Intermeios: São Paulo, 2016.

Leituras imediatas. São Paulo: Ateliê, 2019.

JAKOBSON, R. e POMORSKA, K. Diálogos. São Paulo: Cultrix, 1985.

LEZAMA LIMA, J. Oppiano Licario (Introdução: César López). Madri: Cátedra, 1977. 
LEZAMA LIMA, J. Imagen y posibilidad. Havana: Letras Cubanas, 1981. . Peso del sabor. In: Poesía Completa. Havana: Letras Cubanas, 1985.

. A expressão americana (org. e introdução: Irlemar Chiampi). São Paulo: Brasiliense, 1988. Confluencias (org. Abel Prieto). Havana: Letras Cubanas, 1988a.

MESCHONNIC, H. Spinoza. Poème de la pensée. Paris: CNRS Éditions, 2017.

Artigo recebido em 01/07/2019 e aprovado em 27/08/2019. 